\title{
Plantas autotetraplóides de citros sob tratamento in vitro com colchicina
}

\author{
Rodrigo Rocha Latado(1), Mariângela Cristofani-Yaly(1), Carlos Roberto de Carvalho( ${ }^{(2)}$ \\ e Marcos Antônio Machado(1)
}

\begin{abstract}
(1)Instituto Agronômico, Centro APTA Citros Sylvio Moreira, Rod. Anhanguera, Km 158, CEP 13490-970 Cordeirópolis, SP. E-mail: rodrigo@centrodecitricultura.br, mariangela@centrodecitricultura.br, marcos@centrodecitricultura.br (2)Universidade Federal de Viçosa, Lab. de Citogenética e Citometria, Av. P.H. Rolfs, s/no, CEP 36570-000 Viçosa, MG. E-mail: ccarvalh@ufv.br
\end{abstract}

\begin{abstract}
Resumo - O objetivo deste trabalho foi obter plantas autotetraplóides de tangerina 'Ponkan', laranja 'Pêra-de-abril' e tangor 'Murcott', que serão usadas em cruzamentos com cultivares diplóides, visando à obtenção de indivíduos triplóides sem sementes. Utilizou-se o método de cultivo in vitro de segmentos de epicótilo em meio com colchicina $(0,025,0,05$ e $0,1 \%)$, por diversos períodos $(1,2,3,7$ e 14 dias $)$, com subseqüente regeneração de brotações em meio sem a presença do alcalóide. As brotações foram microenxertadas in vitro e aclimatizadas em estufas. A determinação do nível de ploidia das plantas foi realizada por citometria de fluxo. A colchicina demonstrou ser tóxica aos explantes das três variedades, ocasionando redução significativa no número médio de brotações adventícias e aumento na porcentagem de explantes não-responsivos, em comparação com o controle. Entre as quatro plantas de laranja e uma de tangor obtidas, duas plantas de laranja e a de tangor, demonstraram ser autotetraplóides, apresentando folhas com maior espessura, arredondadas e coloração verde intensa. O método utilizado na duplicação cromossômica, com uso de colchicina, é eficiente em produzir plantas autotetraplóides de citros.
\end{abstract}

Termos para indexação: Citrus, tetraplóide, epicótilo, regeneração in vitro, cultura de tecidos.

\section{Citrus autotetraploid plants obtained by in vitro treatment with colchicine}

\begin{abstract}
The objective of this work was to obtain autotetraploid plants of 'Murcott' tangor, 'Ponkan' mandarin and 'Pêra-de-abril' sweet orange to be used in crosses with diploid cultivars, aiming to produce triploid seedless hybrids. The methodology used was the in vitro culture of epicotyl segments in media containing different concentrations of colchicine ( $0.025,0.05$ and $0.1 \%)$, for several periods of time (1, 2, 3, 7 and 14 days), followed by the regeneration of adventitious shoots in culture media without the alkaloid. All shoots obtained were micrografted, acclimatized and transferred to a greenhouse. The evaluation of the ploidy level of the plants was performed by flow citometry technique. Colchicine was toxic to the explants of three varieties, and caused the reduction on the average number of shoots regenerated per explant as well as an increase in the percentage of non-responsive explants when comparing with the control plants. Among four plants of sweet orange obtained, two of them showed to be autotetraploid. The only plant of tangor obtained also showed to be autotetraploid. These plants presented thicker and roundisher leaves displaying deeper green color. The methodology used resulted efficient for obtaining tetraploid plants.
\end{abstract}

Index terms: Citrus, tetraploid, epicotyl, in vitro regeneration, tissue culture.

\section{Introdução}

As exportações mundiais de laranja e tangerina in natura atingiram em torno de sete milhões de toneladas em 2004. Desse total, o Brasil participou com apenas $1,5 \%$, que correspondem a 108 mil toneladas (Instituto FNP, 2006). Além de questões de ordem fitossanitária, uma das razões para a baixa participação brasileira neste mercado é a inexistência de cultivares que atendam aos requisitos de qualidade exigidos pelo mercado externo de fruta fresca, sendo um dos principais, a exigência de frutos sem sementes (apirenos).

Uma das estratégias para a produção de frutos apirenos é a utilização de cultivares triplóides, como a lima-ácida 'Tahiti' (Citrus latifolia), provavelmente originada de hibridação natural (Luchetti et al., 2003).

Lee (1988) descreveu diversas formas de obtenção de plantas cítricas triplóides $(3 \mathrm{x}=27)$. Entre elas, a obtenção de híbridos sexuais triplóides foi relatada a partir de cruzamentos de cultivares diplóides (2x) com 
tetraplóides (4x) (Esen \& Soost, 1972; Esen et al., 1978) ou de diplóides (2x) com diplóides (2x) (Esen \& Soost, 1971). Neste último cruzamento, os embriões triplóides originaram-se da fertilização de gametas femininos nãoreduzidos (diplóides), com gametas masculinos reduzidos (haplóides). Esen et al. (1978) também descreveram a obtenção de uma planta triplóide na progênie resultante do cruzamento de duas plantas tetraplóides $(4 \mathrm{x})$.

Um dos problemas para o uso mais intenso de cruzamentos envolvendo plantas tetraplóides está no número baixo de cultivares disponíveis. Segundo Soost \& Cameron (1975), a maioria das cultivares de citros tetraplóides foi obtida espontaneamente em populações de plântulas cultivadas para outros fins. No entanto, a frequiência de poliploidização natural nestas populações é geralmente baixa, variando entre 0,2 e $3 \%$ (Barret \& Hutchison, 1978).

Plantas híbridas alotetraplóides ou autotetraplóides em citros também podem ser obtidas com o uso da técnica de hibridação somática via fusão de protoplastos. Utilizando-se esta técnica, vários autores relataram a obtenção de híbridos tetraplóides entre plantas de cultivares de copa do gênero Citrus ou fusionados com plantas de gêneros afins (Grosser et al., 2000; Grosser \& Gmitter, 2005).

Outra maneira de se obter plantas autotetraplóides é pelo uso de colchicina, um alcalóide que tem a capacidade de induzir duplicação cromossômica em células vegetais. Barret (1974) e Wakana et al. (2005) trataram gemas axilares com colchicina, seguido de enxertia, obtendo plantas autotetraplóides. Gmitter \& Ling (1991) usaram este mesmo alcalóide adicionado ao meio de cultura e cultivaram com sucesso óvulos imaturos in vitro, até a regeneração de plantas tetraplóides. Gmitter et al. (1991) e Wu \& Mooney (2002) também obtiveram sucesso, mas com o cultivo in vitro de calos em meio contendo colchicina.

$\mathrm{O}$ aumento na eficiência e a redução no tempo de obtenção de plantas autotetraplóides podem ser obtidos com a utilização de protocolos de alta eficiência de regeneração, como a indução in vitro de brotações adventícias em segmentos de epicótilo (Almeida et al., 2002) ou em segmentos internodais de plantas juvenis (Ghorbel et al., 1998). Com a finalidade de superar problemas de enraizamento in vitro, a microenxertia das brotações regeneradas, sobre porta-enxertos estiolados, tem sido utilizada com sucesso para aumentar a eficiência de recuperação de plântulas (Ghorbel et al., 1998).
O Centro APTA Citros Sylvio Moreira possui um extenso programa de melhoramento de citros, e uma das linhas de pesquisa é a obtenção de tangerinas e híbridos de tangerina triplóides que produzam frutos sem sementes. Para atingir este objetivo, uma das estratégias é obter cultivares tetraplóides, para a realização de cruzamentos com cultivares diplóides.

Este trabalho teve por objetivo a obtenção de plantas autotetraplóides de tangor 'Murcott', tangerina 'Ponkan' e laranja 'Pêra-de-abril', cultivares com características agronômicas superiores, por meio do cultivo de segmentos de epicótilos em meio contendo colchicina, seguido de regeneração de brotações adventícias e microenxertia in vitro.

\section{Material e Métodos}

Os experimentos foram iniciados com a coleta de frutos e a extração de sementes de tangor 'Murcott' [C. sinensis (L.) Osb. x C. reticulata] (CN 221, poliembriônica), tangerina 'Ponkan' $[$ C. reticulata $]$ (CV 172, poliembriônica) e laranja 'Pêra-de-abril' [C. sinensis (L.) Osb.] (CV 148, monoembriônica) do Banco Ativo de Germoplasma do Centro APTA Citros Sylvio Moreira, em Cordeirópolis, SP.

Após esterilização superficial com solução de hipoclorito de sódio, $0,5 \%$ de cloro ativo, as sementes foram lavadas em água destilada autoclavada e colocadas para germinar in vitro no escuro, a $25 \pm 1^{\circ} \mathrm{C}$, durante 30 dias, em meio MS semi-sólido (metade da concentração de sais, sem sacarose, sem vitaminas, acrescido de $7 \mathrm{~g} \mathrm{~L}^{-1}$ de ágar e $\mathrm{pH}$ 6).

Segmentos de epicótilo com $0,5 \mathrm{~cm}$ de comprimento foram seccionados de plantas in vitro e inoculados em placas de Petri contendo meio de cultivo com as diferentes concentrações de colchicina (Mallinckrodt, EUA) $(0,025,0,05$ e $0,1 \%$ p/v) e mantidos por um, dois, três, sete e quatorze dias no escuro em sala de crescimento $\left(25 \pm 1^{\circ} \mathrm{C}\right)$. Cada tratamento correspondeu a uma concentração de colchicina e a um tempo de inoculação no meio contendo colchicina. Após esse período, os explantes foram transferidos para meio sem colchicina e mantidos sob fotoperíodo de 16 horas de $\operatorname{luz}\left(49 \mathrm{mmol} \mathrm{m}^{-2} \mathrm{~s}^{-1}\right)$, por 45 dias.

O meio utilizado para o cultivo de segmentos de epicótilo foi o MT, acrescido de $0,5 \mathrm{~g} \mathrm{~L}^{-1}$ de extrato de malte, $0,1 \mathrm{~g} \mathrm{~L}^{-1}$ de mio-inositol, $50 \mathrm{~g} \mathrm{~L}^{-1}$ de sacarose, $1 \mathrm{mg} \mathrm{L}^{-1}$ de benzilaminopurina (BAP), 7,0 $\mathrm{g} \mathrm{L}^{-1}$ de ágar e pH 6,0. Aproximadamente $3 \mathrm{~g}$ de colchicina foram dissolvidos em $3 \mathrm{~mL}$ de água destilada, filtro-esterilizada 
com filtro $0,22 \mu \mathrm{m}$ e adicionada ao meio de cultura. Para cada tratamento (concentração e tempo de cultivo em colchicina) foram inoculados 30 segmentos de epicótilo, em delineamento inteiramente casualizado. O controle experimental era formado por placas com segmentos de epicótilo cultivados em meio sem colchicina.

Aos 45 dias de cultivo, em cada tratamento foi avaliado o número de brotações regeneradas por explante e o número de explantes não-responsivos, isto é, explantes que não regeneraram nenhuma brotação. Estes dados foram analisados estatisticamente utilizando-se um modelo fatorial $3 \times 3$, considerando-se os fatores tempo de cultivo, um, dois e três dias, e concentração de colchicina, $0,025,0,05$ e $0,1 \% \mathrm{p} / \mathrm{v}$.

Os dados de número de brotações por explante foram transformados em $(x+0,5)^{0,5}$, antes da realização do teste $\mathrm{F}$, a $1 \%$ de probabilidade, e do teste de Tukey, a 5\% de probabilidade, utilizado na comparação das médias dos tratamentos. A porcentagem de explantes não-responsivos foi calculada dividindo-se o número de explantes nãoresponsivos pelo total de explantes inoculados no tratamento.

As gemas adventícias obtidas foram microenxertadas in vitro em plântulas de citrange 'Troyer' (Peña et al., 1995). Cerca de 30 dias após a microenxertia, o conjunto foi enxertado sobre limão 'Cravo' (C. limonia Osbeck) e mantido em câmara úmida em casa de vegetação para a aclimatação, durante 30 dias.

$\mathrm{Na}$ avaliação da ploidia das plantas com o uso de citometria de fluxo, foram utilizadas folhas dos genótipos originais e dos genótipos regenerados. Amostras de folhas jovens foram coletadas, lavadas em água corrente, acondicionadas em ambiente úmido e fresco, entre $4 \mathrm{e}$ $15^{\circ} \mathrm{C}$, e enviadas para o Laboratório de Citogenética e Citometria, da Universidade Federal de Viçosa.

O equipamento utilizado nas análises foi o citômetro PAS II-III (Partec Gmbh., Alemanha), equipado com lâmpada HBO 100 W e filtros kg1, BG 38 e CG 435. As suspensões nucleares foram isoladas e coradas com o tampão do kit CyStain UV precise T-DAPI (Partec Gmbh.), que usa o 4-6-diamidino-2-fenilindole (DAPI) como fluorocromo, seguindo-se as recomendações do fabricante. Cada amostragem, com não menos que 4.000 núcleos, foi avaliada com uso do software FlowMax v 2.6 (Partec Gmbh.), na forma de três repetições por planta. As amostras cujos coeficientes de variação se situaram acima de 5\% foram descartadas. Os histogramas gerados pelo software foram calibrados para um parâmetro (Side Scatter - SSC) e dimensionados com resolução em escala linear com 10 bits (1.024 pixels).

Na caracterização morfológica de folhas, avaliaramse o comprimento, largura e espessura do limbo foliar, das plantas autotetraplóides e das plantas do controle, com auxílio de um paquímetro digital. Para tal, foram destacadas cinco folhas superiores de cada planta (com comprimento mínimo de $4 \mathrm{~cm}$ ) e realizadas as medições. A relação entre comprimento e largura (razão $\mathrm{C} / \mathrm{L}$ ) do limbo foliar também foi calculada para cada amostra.

Os dados foram analisados estatisticamente utilizandose um delineamento inteiramente casualizado, com modelo contendo apenas o fator tratamento. Os dados não foram transformados antes da realização do teste $\mathrm{F}$, a $1 \%$ de probabilidade, e do teste de Tukey, a 5\% de probabilidade, utilizado na comparação das médias dos tratamentos.

\section{Resultados e Discussão}

A colchicina demonstrou ser tóxica aos explantes de laranja 'Pera-de-abril' e de tangor 'Murcott', ocasionando reduções significativas no número médio de brotações adventícias obtidas e aumento na porcentagem de explantes não-responsivos, em comparação com o controle, em diversas concentrações de colchicina e tempos de cultivo testados (Tabela 1). Quanto aos explantes de laranja 'Pera-de-abril', cultivados durante um dia em colchicina, o incremento de 0,025 para $0,1 \%$ na concentração do alcalóide, resultou em redução de 0,47 para 0,1 no número médio de brotações regeneradas por explante, ao passo que no controle, a média obtida foi de 0,65 brotação por explante. Quanto à porcentagem de explantes não-responsivos de laranja, cultivados durante um dia em colchicina, observou-se $45 \%$ no controle, $60 \%$ na concentração de $0,025 \%$, alcançando $90 \%$ na concentração de $0,1 \%$.

Nas cultivares laranja 'Pêra-de-abril' e tangor 'Murcott', o fator tempo de cultivo afetou mais significativamente o número de brotações regeneradas ( $\mathrm{F}=14,0 * *$ e $\mathrm{F}=7,9 * *$, respectivamente), ao passo que o fator concentração de colchicina causou efeito menor para o tangor $\left(\mathrm{F}=3,6^{*}\right)$ e foi não-significativo, para a laranja $\left(\mathrm{F}=1,8^{\mathrm{ns}}\right)$. Nessas variedades, a maioria das brotações foi obtida nos tratamentos mantidos por um dia em meio contendo colchicina, independentemente da concentração testada (Tabela 1). A tangerina 'Ponkan' apresentou explantes com baixa taxa de regeneração, mesmo no controle, não sendo possível observar 
diferenças entre os explantes tratados com as diversas concentrações de colchicina e os do controle $\left(\mathrm{F}=2,2^{\mathrm{ns}}\right)$.

Na inoculação de explantes por período mais longo, 7 e 14 dias, a colchicina suprimiu completamente a capacidade de regeneração de brotações adventícias em todas as concentrações e cultivares testadas. Os sintomas de toxidez e mortalidade por colchicina foram o escurecimento e a degeneração das pontas dos segmentos, com evidente morte da região do câmbio (Figura 1).

Tabela 1. Número médio de brotações adventícias obtidas por segmento de epicótilo e porcentagem de explantes não responsivos de laranja 'Pêra-de-abril', tangor 'Murcott' e tangerina 'Ponkan', após tratamento com diferentes concentrações de colchicina e em diferentes tempos de cultivo $^{(1)}$.

\begin{tabular}{cccll}
\hline $\begin{array}{c}\text { Tempo } \\
(\text { dias })\end{array}$ & $\begin{array}{c}\text { Colchicina } \\
(\%)\end{array}$ & $\begin{array}{c}\text { Laranja } \\
\text { 'Pera-de-abril' }\end{array}$ & $\begin{array}{c}\text { Tangor } \\
\text { 'Murcott' }\end{array}$ & $\begin{array}{c}\text { Tangerina } \\
\text { 'Ponkan' }\end{array}$ \\
\hline & Controle & $0,65(45)$ & $0,69(40)$ & $0,13(90)$ \\
\hline 1 & 0,025 & $0,47 \mathrm{a}(60)$ & $0,44 \mathrm{a}(65)$ & $0,05(95)$ \\
& 0,05 & $0,31 \mathrm{a}(75)$ & $0,18 \mathrm{a}(80)$ & $0,22(80)$ \\
& 0,1 & $0,10 \mathrm{a}(90)$ & $0,00 \mathrm{~b}(100)$ & $0,00(100)$ \\
\hline 2 & 0,025 & $0,00 \mathrm{~b}(100)$ & $0,00 \mathrm{~b}(100)$ & $0,00(100)$ \\
& 0,05 & $0,00 \mathrm{~b}(100)$ & $0,00 \mathrm{~b}(100)$ & $0,05(95)$ \\
& 0,1 & $0,00 \mathrm{~b}(100)$ & $0,00 \mathrm{~b}(100)$ & $0,00(100)$ \\
\hline 3 & 0,025 & $0,00 \mathrm{~b}(100)$ & $0,04 \mathrm{~b}(95)$ & $0,00(100)$ \\
& 0,05 & $0,00 \mathrm{~b}(100)$ & $0,00 \mathrm{~b}(100)$ & $0,00(100)$ \\
& 0,1 & $0,00 \mathrm{~b}(100)$ & $0,00 \mathrm{~b}(100)$ & $0,00(100)$ \\
\hline
\end{tabular}

(1)Médias seguidas pela mesma letra, na coluna, não diferem entre si pelo teste de Tukey, a 5\% de probabilidade; valores entre parênteses referem-se às porcentagem de explantes não-responsivos.

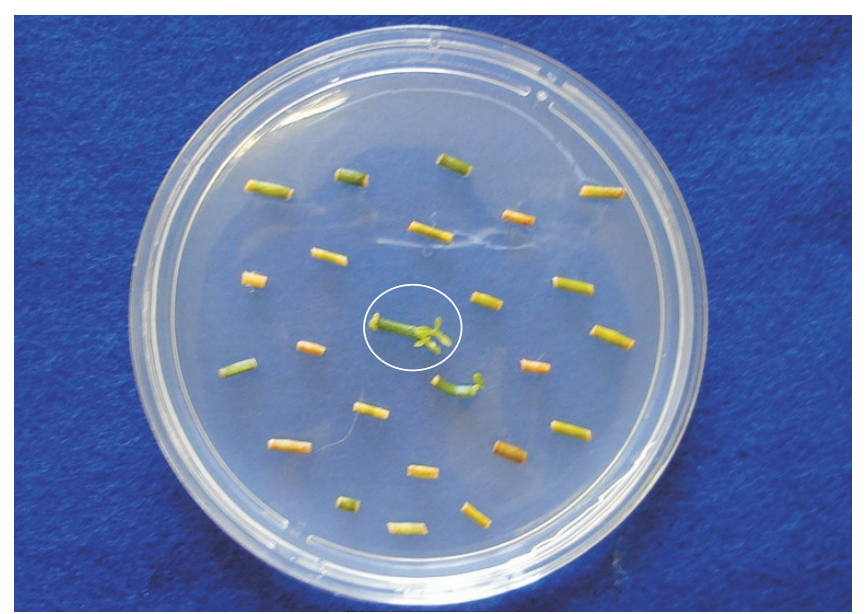

Figura 1. Segmentos de epicótilo de laranja 'Pêra-de-abril', cultivados em meio MT com colchicina $(0,1 \%)$. Em destaque, a regeneração de brotações adventícias.
Os efeitos nocivos do tratamento de células e tecidos vegetais com colchicina foram relatados por vários autores. Gmitter et al. (1991), Gmitter \& Ling (1991) e Wu \& Mooney (2002) observaram reduções na capacidade de regeneração e até a mortalidade de calos e de óvulos imaturos de várias espécies de citros em meio com colchicina. Mesmo sem utilizar cultura de tecidos, Wakana et al. (2005) observaram reduções no desenvolvimento de ramos e na taxa de pegamento de enxertos de três espécies de Citrus, cujas estacas foram tratadas com solução contendo $0,8 \%$ de colchicina.

Embora os procedimentos utilizados neste trabalho assegurem melhor taxa de recuperação do material cultivado in vitro, ocorreram perdas por problemas de enxertia e aclimatização. Em conseqüência disso, foram obtidas somente quatro plantas de laranja 'Pêra-de-abril', uma de tangor 'Murcott' e nenhuma de tangerina 'Ponkan'.

Nas análises por citometria de fluxo das suspensões nucleares obtidas das folhas destas cinco plantas, os picos de leitura da quantidade de DNA em $\mathrm{G}_{1}$, após a coloração com DAPI, resultaram em histogramas com resoluções suficientemente claras para identificar as plantas diplóides e as tetraplóides (Figura 2). Entre as quatro plantas de laranja 'Pêra-de-abril' analisadas, duas apresentaram-se como tetraplóides, R5PT02 e R6PT05, ambas originadas do tratamento de segmentos de epicótilo com $0,05 \%$ de colchicina (Tabela 2). A única planta de tangor 'Murcott' aclimatizada, R5PT04, também
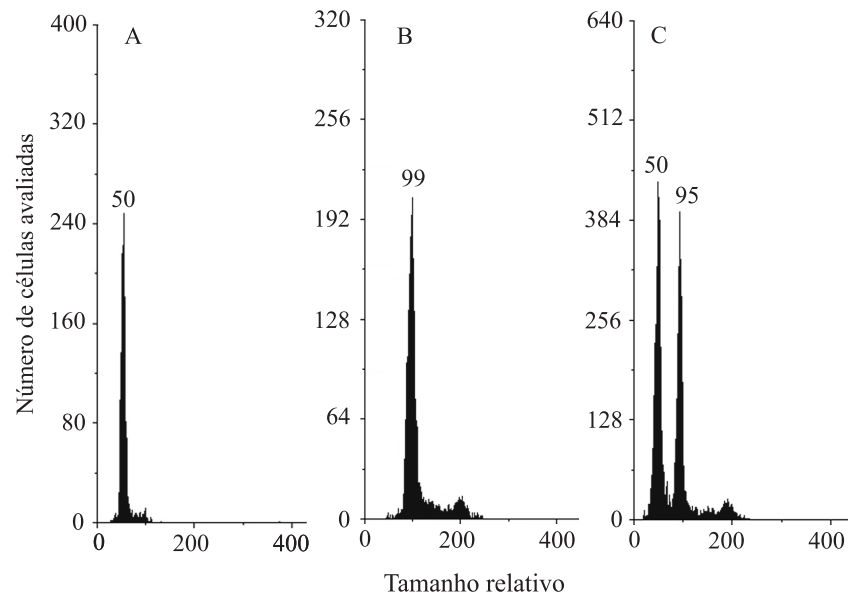

Figura 2. Histogramas obtidos com as análises por citometria de fluxo de suspensões nucleares. A) tangor 'Murcott' controle 2x; B) tangor 'Murcott' 4x; C) laranja 'Pêra-de-abril' controle 2x e laranja 'Pêra-de-abril' 4x. 
demonstrou ser tetraplóide. Todas as plantas do controle apresentaram-se como diplóides.

As três plantas autotetraplóides obtidas apresentaram estabilidade, demonstrada pelo método de citometria de fluxo. A hipótese da existência de mixoploidia nas plantas autotetraplóides foi descartada, uma vez que foram colhidas três amostras de folhas, de diferentes posições de cada uma das plantas obtidas, e estas três amostras foram avaliadas separadamente.

A estabilidade pode ser explicada pelo método de cultura de tecidos empregado, isto é, o cultivo in vitro de segmentos de epicótilo com subseqüente regeneração de gemas adventícias. Isto por já ter sido comprovado que, neste caso, as brotações adventícias originam-se de uma ou poucas células do tecido do câmbio, o que resulta na regeneração de plantas não-quiméricas (Almeida, 2002).

Os métodos de indução in vivo de autotetraplóides pela adição de colchicina em ramos, gemas axilares, gemas apicais e sementes, geralmente resultam em plantas quiméricas, contendo setores autotetraplóides instáveis, devido ao fato de o tratamento com o agente antimitótico ser aplicado em tecidos que contêm meristemas multicelulares (Gmitter et al., 1991; Wu \& Mooney, 2002; Wakana et al., 2005). A estabilização desses setores e a obtenção de plantas completamente tetraplóides, muitas vezes só é alcançada após a realização de propagações vegetativas ou sexuais, da planta quimérica (Wakana et al., 2005).

Quanto ao método utilizado para confirmar a ploidia das plantas, Gmitter et al. (1991), Gmitter \& Ling (1991) e Wakana et al. (2005) utilizaram a contagem de número de cromossomos, ao passo que Wu \& Mooney (2002) preferiram usar a análise de citometria de fluxo para identificar a ploidia, enquanto a contagem do número cromossômico foi utilizada apenas para confirmar a natureza poliplóide. Neste último estudo, os autores

Tabela 2. Dados obtidos das análises por citometria de fluxo de suspensões nucleares de folhas de citros coradas com o fluorocromo DAPI.

\begin{tabular}{lccc}
\hline Cultivar & Leitura $\left(\mathrm{G}_{1}\right)$ & Index $^{(1)}$ & Ploidia \\
\hline Tangor Murcott controle & 50 & 1,00 & $2 \mathrm{x}$ \\
Tangor Murcott (R5PT04) $^{(2)}$ & 99 & 1,98 & $4 \mathrm{x}$ \\
Laranja Pêra-de-abril controle $^{(2)}$ & 50 & 1,00 & $2 \mathrm{x}$ \\
Laranja Pêra-de-abril (R5PT02) & 93 & 1,86 & $4 \mathrm{x}$ \\
Laranja Pêra-de-abril (R5PT03) & 49 & 0,98 & $2 \mathrm{x}$ \\
Laranja Pêra-de-abril (R6PT05) & 95 & 1,90 & $4 \mathrm{x}$ \\
Laranja Pêra-de-abril (R6PT06) & 48 & 0,96 & $2 \mathrm{x}$ \\
\hline
\end{tabular}

${ }^{(1)} \mathrm{O}$ index 1 foi atribuído ao canal de leitura 50 do padrão (tangor 'Murcott' controle). (2)Planta padrão-diplóide. afirmam que o método de citometria de fluxo apresentou rapidez e precisão suficiente para distinguir as plantas tetraplóides das diplóides e para identificar uma planta mixoplóide, que continha setores tetraplóides e diplóides juntos.

Os dados da caracterização morfológica das folhas mostraram que todas as plantas autotetraplóides obtidas apresentaram folhas com espessura média significativamente maior e com relação comprimento/ largura $(\mathrm{C} / \mathrm{L})$ menor, em relação às plantas controle (Tabela 3), resultando numa tendência a possuírem folhas com formato mais arredondado (Figura 3). Com relação à coloração, plantas autotetraplóides apresentaram folhas com coloração verde mais intensa do que as das plantas do controle. Essas mesmas características também foram descritas por vários outros autores (Gmitter \& Ling, 1991; Wakana et al., 2005). Por sua vez, Wu \& Mooney (2002) observaram plantas autotetraplóides de tangor 'Umatilla' com folhas de menor comprimento e largura do que as da cultivar original.

Uma das vantagens do método foi o curto período de tempo aplicado na obtenção das plantas in vitro (75 dias), bem como na aclimatização ao meio ambiente e na identificação das plantas autotetraplóides, aproximadamente mais 30 a 60 dias. Outros relatores afirmaram ter conseguido regenerar embriões in vitro de citros somente após cinco ou seis meses do tratamento com a colchicina (Gmitter \& Ling, 1991; Wu \& Mooney, 2002).

O material obtido está sendo incorporado ao programa de melhoramento, sendo sobrenxertado em plantas adultas para reduzir a juvenilidade, antes de serem usados nos cruzamentos.

Tabela 3. Médias de comprimento, largura, relação comprimento/largura (CL) e espessura de folhas de plantas autotetraplóides de laranja 'Pera-de-abril', tangor 'Murcott' e dos respectivos controles ${ }^{(1)}$.

\begin{tabular}{lcccc}
\hline Cultivar & $\begin{array}{c}\text { Comprimento } \\
(\mathrm{cm})\end{array}$ & $\begin{array}{c}\text { Largura } \\
(\mathrm{cm})\end{array}$ & $\begin{array}{c}\mathrm{C} / \mathrm{L} \\
\text { Espessura } \\
(\mathrm{mm})\end{array}$ \\
\hline Pêra-de-abril controle & 56,29 & $28,22 \mathrm{~b}$ & $2,00 \mathrm{a}$ & $0,20 \mathrm{~b}$ \\
Pêra-de-abril (R5PT02) 4x & 48,44 & $29,84 \mathrm{~b}$ & $1,63 \mathrm{~b}$ & $0,27 \mathrm{a}$ \\
Pêra-de-abril (R6PT05) 4x & 54,11 & $36,21 \mathrm{a}$ & $1,49 \mathrm{~b}$ & $0,30 \mathrm{a}$ \\
\hline F & $4,9^{\text {ns }}$ & $20,7^{* *}$ & $35,2^{* *}$ & $41,7^{* *}$ \\
CV (\%) & 7,7 & 6,6 & 5,8 & 7,2 \\
\hline Murcott controle & 56,38 & $29,89 \mathrm{~b}$ & $1,89 \mathrm{a}$ & $0,18 \mathrm{~b}$ \\
Murcott (R5PT04) 4x & 62,75 & $46,78 \mathrm{a}$ & $1,34 \mathrm{~b}$ & $0,28 \mathrm{a}$ \\
\hline F & $10,32^{\text {ns }}$ & $489,7^{* *}$ & $107,5^{* *}$ & $88,4^{* *}$ \\
CV (\%) & 5,3 & 3,1 & 5,2 & 6,9 \\
\hline
\end{tabular}

${ }^{(1)}$ Médias seguidas pela mesma letra, na coluna, não diferem entre si pelo teste de Tukey, a $5 \%$ de probabilidade. ${ }^{*}$ Significativo a $1 \%$ de probabilidade, pelo teste $\mathrm{F}$. 

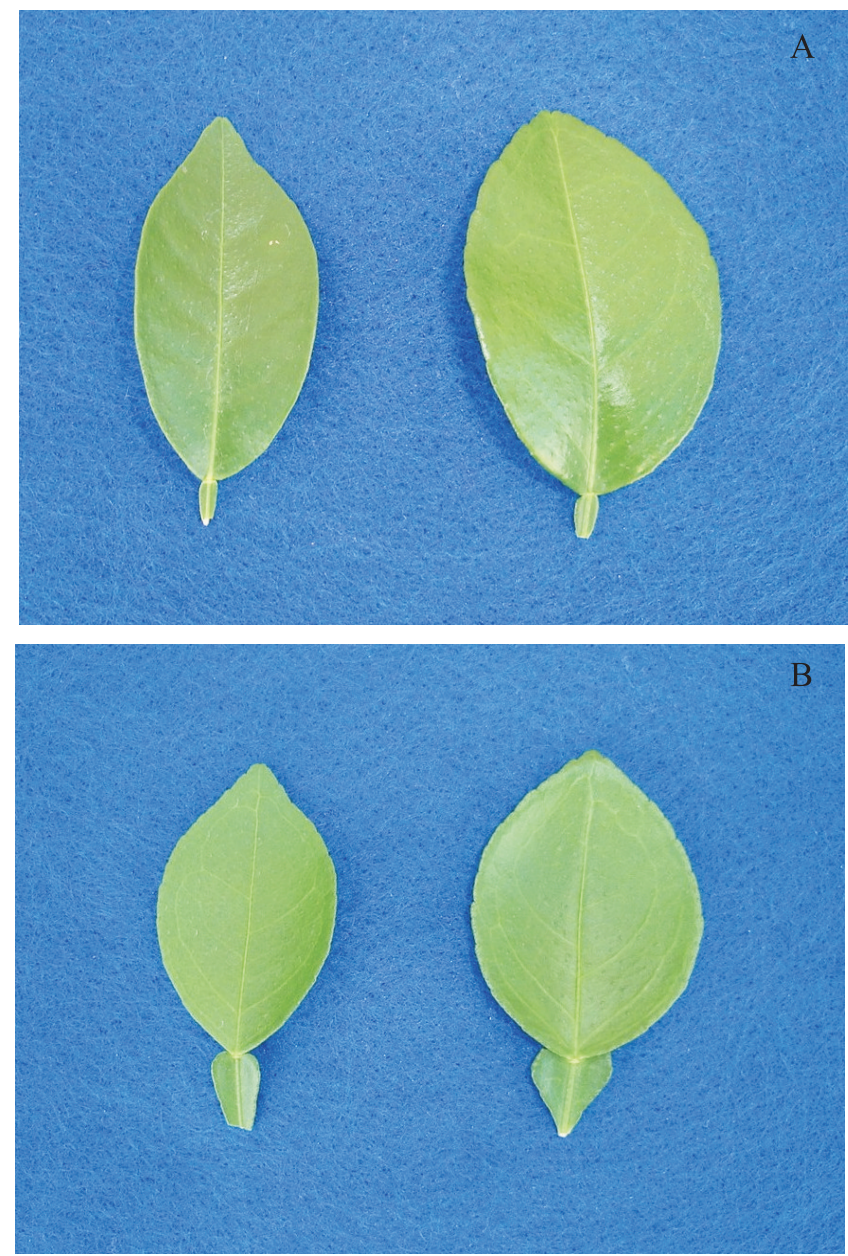

Figura 3. A: folhas de tangor 'Murcott' do controle (esquerda) e autotetraplóide (direita); B: folhas de laranja 'Pêra-de-abril' do controle (esquerda) e autotetraplóide (direita).

\section{Conclusão}

O cultivo de segmentos de epicótilos de citros em meio contendo colchicina, seguido de regeneração de brotações adventícias e microenxertia in vitro é eficiente na produção de plantas autotetraplóides.

\section{Agradecimentos}

À Fapesp, pelo apoio; ao CNPq, pela bolsa de produtividade em pesquisa.

\section{Referências}

ALMEIDA, W.A.B. Caracterização anatômica da organogênese in vitro e transformação genética via Agrobacterium tumefaciens em Citrus sp. 2002. 138p. Tese (Doutorado) - Universidade de São Paulo, Piracicaba.

ALMEIDA, W.A.B.; MOURÃO FILHO, F.A.A.; MENDES, B.M.J.; RODRIGUEZ, A.P.M. In vitro organogenesis optimization and plantlet regeneration in Citrus sinensis and C. limonia. Scientia Agricola, v.59, p.35-40, 2002.

BARRET, H.C. Colchicine-induced polyploidy in Citrus. Botanical Gazette, v.135, p.29-41, 1974.

BARRET, H.C.; HUTCHISON, D.J. Spontaneous tetraploidy in apomitic seedlings of Citrus. Economic Botany, v.32, p.27-45, 1978.

ESEN, A.; SOOST, R.K. Tetraploid progenies from $2 \mathrm{x}$ X 4x crosses of Citrus and their origin. Journal of the American Society for Horticultural Science, v.97, p.410-414, 1972.

ESEN, A.; SOOST, R.K. Unexpected triploids in Citrus: their origin, identification, and possible use. Journal of Heredity, v.62, p.329333, 1971.

ESEN, A.; SOOST, R.K.; GERACI, G. Seed set, size, and development after 4x X 2x and 4x X 4x crosses in Citrus. Euphytica, v.27, p.283-294, 1978.

GHORBEL, R.; NAVARRO, L.; DURAN-VILA, N. Morphogenesis and regeneration of whole plants of grapefruit (Citrus paradisi), sour orange (C. aurantium) and alemow (C. macrophylla). Journal of Horticultural Science \& Biotechnology, v.73, p.323-327, 1998.

GMITTER, F.G.; LING, X. Embryogenesis in vitro and non chimeric tetraploid plant recovery from undeveloped citrus ovules treated with colchicines. Journal of the American Society for Horticultural Science, v.116, p.317-321, 1991.

GMITTER, F.G.; LING, X.; CAI, C.; GROSSER, J.W. Colchicineinduced polyploidy in Citrus embryogenic cultures, somatic embryos, and regenerated plantlets. Plant Science, v.74, p.135-141, 1991.

GROSSER, J.W.; GMITTER, F.G. Applications of somatic hybridization and cybridization in crop improvement, with citrus as a model. In vitro Cellular \& Developmental Biology-Plant, v.41, p.220-225, 2005.

GROSSER, J.W.; OLLITRAULT, P.; OLIVARES-FUSTER, O. Somatic hybridization in citrus: an effective tool to facilitate variety improvement. In vitro Cellular \& Developmental Biology-Plant, v.36, p.434-449, 2000.

INSTITUTO FNP. Agrianual 2006: anuário da agricultura brasileira. São Paulo: FNP, 2006. 504p.

LEE, L.S. Citrus polyploidy: origins and potential for cultivar improvement. Australian Journal of Agricultural Research,v.39, p.735-747, 1988.

LUCHETTI, M.A.; MATTOS JÚNIOR, D.; NEGRI, J.D. de; FIGUEIREDO, J.O. Aspectos gerais e distribuição. In: MATTOS JÚNIOR, D.; NEGRI, J.D. de; FIGUEIREDO, J.O. (Ed.). Lima ácida Tahiti. Campinas: Instituto Agronômico, 2003. p.1-12.

PEÑA, L.; CERVERA, M.; JUAREZ, J.; ORTEGA, C.; PINA, J.A.; DURAN-VILA, N.; NAVARRO, L. High efficiency Agrobacterium-mediated transformation and regeneration of Citrus. Plant Science, v.104, p.183-191, 1995. 
SOOST, R.K.; CAMERON, J.W. Citrus. In: JANNICK, J.; MOORE, J.N. (Ed.). Advances in fruit breeding. West Lafayette: Purdue University Press, 1975. p.507-540.

WAKANA, A.; HANADA, N.; PARK, S.M.; FUKUDOME, I.; KAJIWARA, K. Production of tetraploid forms of acid citrus cultivars by top grafting of shoots with sprouting axially buds treated with colchicines Journal of the Faculty of Agriculture Kyushu University, v.50, p.93-102, 2005.

WU, J.H.; MOONEY, P. Autotetraploid tangor plant regeneration from in vitro citrus somatic embryogenic callus treated with colchicines. Plant Cell, Tissue and Organ Culture, v.70, p.99104, 2002.

Recebido em 1ㅇ de março de 2007 e aprovado em 27 de agosto de 2007 